\title{
Analysis of a Concrete Structure that Was Exposed to Fires in the Metropolitan Region of Recife
}

\author{
Romildo Alves Berenguer ${ }^{1}$, Adauto de Holanda Barbosa ${ }^{2}$, Eliana Cristina Barreto Monteiro ${ }^{1,2}$, Romilde Almeida \\ de Oliveira ${ }^{1}$ and Angelo Just da Costa e Silva ${ }^{1,2}$ \\ 1. Department of Civil Engineering, Catholic University of Pernambuco, Recife 51110-200, Brazil \\ 2. Department of Civil Engineering, University of Pernambuco, Recife 51110-200, Brazil
}

\begin{abstract}
In large cities, news about fires in buildings are powered by problems such as old wiring and no maintenance. Accidents with chemicals and human error, which when added to the different characteristics of each fire and structures can generate the factors causing these disasters. The gradual rise in temperature causes a different effect in mortar and concrete parts, verifying the change in coloring provided to loss of mechanical strength and surface crumbling, cracking and disintegration of the structure itself. This paper presents a case study in which a building that is located in the metropolitan region of Recife was exposed to a fire situation. The metropolitan region of Recife is composed of several old buildings that by virtue of their age may have delayed construction methods, and may expose the fragility of the concrete used in its construction on a fire situation. The concrete structures are recognized by the good resistance to fire because of the thermal characteristics of the material, however, the temperature rise in the concrete elements in characteristic causes a reduction in strength and modulus of elasticity of the material, the loss in stiffness leading to polyphase degradation of reinforced concrete, structural parts can lead to ruin, but when properly sized and executed, the concrete can serve as a proactive agent to be exposed to high temperatures, as the same may be subjected to high temperatures accidentally or they may be part of their normal work.
\end{abstract}

Key words: Awning, pathological manifestations, durability.

\section{Introduction}

Among many other definitions, we can say that a fire situation is when the element of fire reaches dimensions that can get out of control of man and can be extremely dangerous for the living beings, and for the structures in general, having the ability to cause damage to property and life by the action of flames, heat and smoke. This way, when the accident occurs, many problems are manifested due to the increase of the temperature to which it was before exposed.

An interesting point is the behavior of water existing in the structures, which when exposed to large temperature variations, has its thermal expansion influenced on the process of concrete chipping, or by effects like sloughing or explosive spalling, occurring

Corresponding author: Romildo Alves Berenguer, professor, research fields: concrete, corrosion materials and structural concrete. by factors such as the onset temperature and pressure gradients associated with the vaporization and transport of large amount of water [1].

Studying the fire in a building is understanding how fire behaves when it propagates through the structure, which can be aggravated when they are in disagreement with the standards. Safety against fires is the branch of engineering that focuses on the preservation of life. It is an area where multidisciplinarity is very developed and its dynamic results come from the interaction of professionals from the fields of civil, electrical, mechanical engineering, and others. It is an activity where a number of interests are involved, where we can mention the insurers, who are responsible for building the state and as an organ which oversees manufacturers of firefighting equipment, materials engineers who develop materials, so that if the 
collapse of the building happens, it is the latest possible.

\section{Bibliographic Review}

\subsection{Effects of Fire in Concrete Structures}

Composed of different materials, concrete and its different constituents do not react the same way at high temperatures, which is a serious problem when studying the exposure of a structure to a fire.

According to Refs. [2-6], typical cycles of a fire consist of three parts: initial, intermediate and final.

\subsubsection{Initial}

This stage is where the gradual increase of the temperature, commonly in a short time. But below $250{ }^{\circ} \mathrm{C}$, the effect of this rise in temperature does not influence both the properties of mechanical resistance of the concrete. At this stage it is possible to reach $300{ }^{\circ} \mathrm{C}$, where it begins to accentuate the loss of strength of concrete, which can be rather worsened in accordance with the situations that involve sudden cooling of concrete.

\subsubsection{Intermediate}

During the transition phase between the initial and intermediate parts, or living combustion phase, there is a huge rise in temperature in a short period, which presents the uncontrolled spread of flame, to the point of irreversibility of fire or point of flash over which rarely exceed the values of $1,250 \sim 1,300{ }^{\circ} \mathrm{C}$.

\subsubsection{Final}

The main characteristic of this last phase is the reduction of the fire to its extinction, as well as how the concrete structure is influenced according to how the fire is extinguished. The cooling of the element when performed suddenly, is primarily responsible for the major concrete strength losses. When this cooling is done in a controlled so that it is processed slowly, there is a possibility of up to $90 \%$ recovery of strength before exposure to high temperatures.

According to Refs. [3-5], there are three thermal properties that may be significant in the specific performance: the coefficient of thermal expansion, specific heat and thermal conductivity. The coefficient of thermal expansion is determined by the value that accounts for the concrete, but their influence depends on the aggregated content and the proportions of the mixture overall. If the coefficient of thermal expansion of the aggregates differs by more than $5.5 \times 10^{-6} /{ }^{\circ} \mathrm{C}$ than the cement paste, the durability of concrete can be adversely affected. Minor differences between the thermal expansion of the cement paste and aggregate are not harmful, within the temperature range of $4 \sim 60{ }^{\circ} \mathrm{C}$, because of the modifying effects of shrinkage and deformation. Table 1 shows the thermal expansion coefficients of the most common produced from aggregates which are between 5 and $13 \times 10^{-6} /{ }^{\circ} \mathrm{C}$. For Portland hydrated cement mortar, the coefficient generally lies between 11 and $6 \times 10^{-6} /{ }^{\circ} \mathrm{C}$, depending only on the degree of saturation.

According to Ref. [3], basalt is shown as an aggregate with low conductivity. Limestone and dolomite appear as intermediate conductivity aggregates, and quartz is displayed with high thermal conductivity indices. That is with the direction of flow heat relative orientation of the crystals, because the crystallinity of the material increases its thermal conductivity. The thermal expansion coefficient varies with different types of concrete and the temperature, but the resistance of concrete to temperature variations is inversely proportional to its coefficient of thermal expansion. So due to the proximity of thermal expansion between steel $\left(11.9 \times 10^{-6} /{ }^{\circ} \mathrm{C}\right)$ and the concrete $\left(10 \times 10^{-6} /{ }^{\circ} \mathrm{C}\right)$, the use of these materials together

Table 1 Linear coefficient of thermal expansion for different aggregates [3].

\begin{tabular}{lll}
\hline Aggregate type & \multicolumn{2}{l}{ Expansion coefficient thermal } \\
\cline { 2 - 3 } & $10^{-6} \mathrm{per}^{\circ} \mathrm{C}$ & $10^{-6} \mathrm{per}^{\circ} \mathrm{F}$ \\
\hline Granite & $1.8 \sim 11.9$ & $1.0 \sim 6.6$ \\
Diorite/andesite & $4.1 \sim 10.3$ & $2.3 \sim 5.7$ \\
Gabbro, basalt, diabase & $3.6 \sim 9.7$ & $2.0 \sim 5.4$ \\
Sandstone & $4.3 \sim 13.9$ & $2.4 \sim 7.7$ \\
Dolomite & $6.7 \sim 8.6$ & $3.7 \sim 4.8$ \\
Calcareous & $0.9 \sim 12.2$ & $0.5 \sim 6.8$ \\
Quartz variety & $7.4 \sim 13.1$ & $4.1 \sim 7.3$ \\
Marble & $1.1 \sim 16.0$ & $0.6 \sim 8.9$ \\
\hline
\end{tabular}


results in optimum performance of the chassis, but their heat transfer coefficients are very different: concrete being an insulator thermal and steel a great conductor of heat.

\subsection{Effects of Exposure to High Temperatures in the Chemical Composition of Concrete}

The chemical consequences of rising temperatures are very diverse, among them we can mention the superficial crumbling given the calcined layer, the partial separation of small layers of material during the fire, delamination or deep peeling and chipping explosives. The phenomenon that characterizes the delamination or deep peeling is also known as "sloughing", an effect which we can observe the posting of concrete slabs over large areas of the surface and the appearance of cracks. The effect generated by the posting of signs, but abruptly and violently is called "explosive spalling", and it usually occurs in the first 30 minutes of the fire action with average temperatures between $250^{\circ} \mathrm{C}$ and $400{ }^{\circ} \mathrm{C}$.

\subsection{Effects of Exposure to High Temperatures in the Physical Composition of Concrete}

There are several registers in the technical literature which show that there are variations in the specific color when it is exposed to high temperatures, showing pink tones at lower temperatures, through gray to intermediate temperatures, up to whitish yellow for high temperatures. In Table 2, we can see the changing in color, visual appearance, and performance of the concrete piece exposed to various temperatures.

\subsection{Chipping in Buildings}

Chipping is the definition of a state when the concrete shows if you have been exposed to the action of fire, is characterized by the separation of the outer layers and its interior is a complex reaction phenomenon between the constraints imposed by temperature gradients in the part, chemical and physical
Table 2 Physical effects in concrete exposed to fire [2, 3].

\begin{tabular}{lll}
$\begin{array}{l}\text { Temperature } \\
\left({ }^{\circ} \mathrm{C}\right)\end{array}$ & Color & Visual appearance/performance \\
\hline$<250$ & Grey & Loss of resistance and irregular \\
\hline $285 \sim 300$ & Gray-rosy & $\begin{array}{l}\text { Surface cracking, chipping } \\
\text { explosive (steam) }\end{array}$ \\
\hline 300 & Rosy & Color-changing home \\
\hline $50 \sim 400$ & & Reduced modulus of elasticity \\
\hline $535 \sim 550$ & Purple & deep cracks-friability surface \\
\hline 575 & Pale red & Pipocamento of quartz grains \\
\hline 650 & Whitish gray & Loss of mechanical properties \\
\hline $790 \sim 800$ & & $\begin{array}{l}\text { Chipping the pools coating } \\
\text { armor, with exposure up to 25\% } \\
\text { surface thereof }\end{array}$ \\
\hline 900 & & Orange yellow Puverulenta surface \\
\hline 1,000 & Pale yellow &
\end{tabular}

reactions that decrease the strength and ductility of the material and the cooling element from the sudden damping of the structure that was previously dried.

Due to thermal shock during cooling, the elements develop internal vapor pressures in the concrete microstructure, which increase according to the intensity of heat, heating rate, armor covering works, dimensions and shape of the part. These pressures can reach the breaking level of resistance to draw concrete, resulting in the expulsion of the material, which may be slow or sudden.

This phenomenon can take an unpredictable character, during the first minutes of fire [4]. The chippings have been classified according to disintegration, the extent of damage, and the occurrence time during the heating period [7].

\section{Results (Case Study)}

\subsection{Fire Description}

On the second week of February 2014, between 12:00 p.m and 1:00 p.m, there was a fire in a building in the metropolitan region of Recife, Brazil. The flames reached not only the adjacent rooms, but also the apartments on the upper and lower floors, as shown in Fig. 1.

According to the newspapers [8-11], the fire started in one of the rooms of the apartment, but all the 


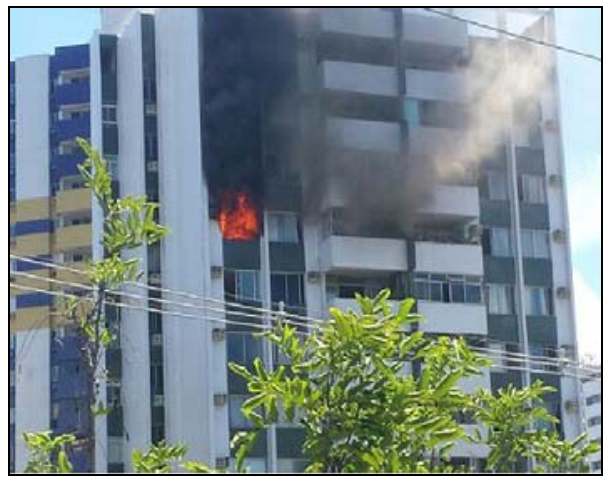

Fig. 1 Fire in the apartment reflected in the upper and lower apartment [8].

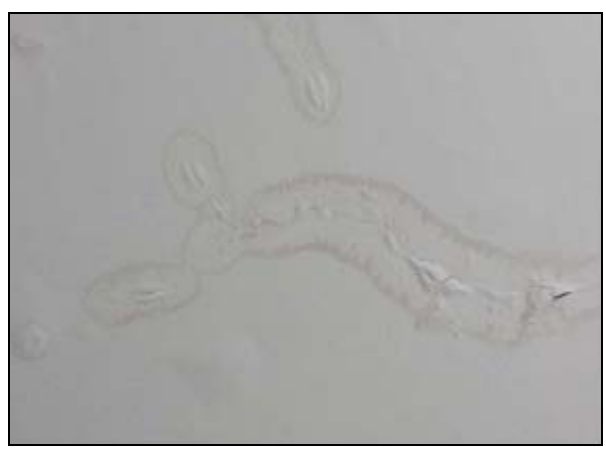

Fig. 2 Damage to the apartment ceiling painting.

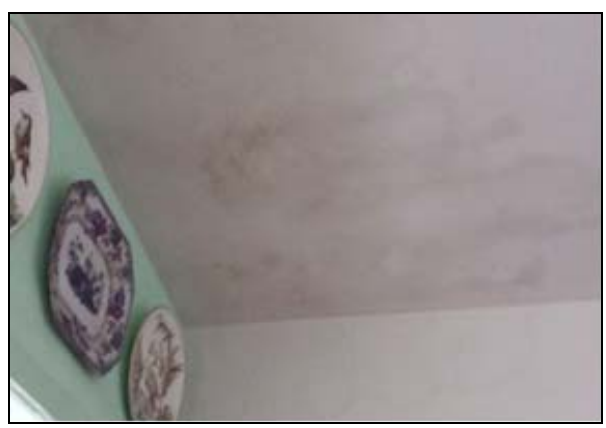

Fig. 3 Damage to the living room ceiling.

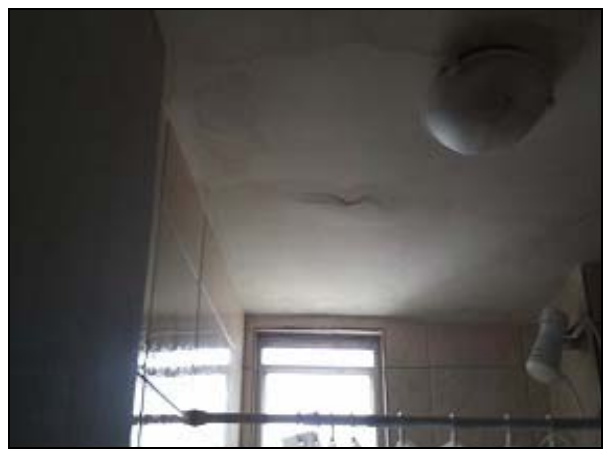

Fig. 4 Damage on the bathroom ceiling painting plaster.

inhabitants managed to leave their places in safety. It was then requested by the representative of the residents a technical opinion which this case study is based on, and had been a guideline to analyze the structural conditions of the building elements, after the occurrence of the accident.

\subsection{Work Description}

The structure of the building was 40 years old and presented itself in reinforced concrete, with 12 floors and two apartments per floor. The walls were made of ceramic blocks, the coating on the walls contained clay internally, and its slabs were the Volterrana type, filling their spaces with concrete blocks.

\subsection{Consulted Documents}

The following were consulted for the preparation of the technical report: the architectural design of floor plan of the paving; the occurrence certificate issued in the state of Pernambuco from the Fire Department; the expert report from the Crime Lab; and three inspections, where the data were collected forming the basis for the discussion that made the technical opinion. According to the report of the Crime Lab, a short circuit in the shower near the room where the event started would most likely be the cause of the fire, due to the existence of a wardrobe and the wooden door that separated the two rooms.

\section{Discussion}

\subsection{Analysis of Damages Observed in the Constructive} Elements and Recommended Procedures.

The fire caused damages to a bedroom, bathroom and balcony of the apartment, reaching the downstairs apartment's ceiling, floor and balcony of the upstairs apartment.

\subsection{Lower Apartment}

The damages to the lower apartment were highlighted in the ceiling of the bedroom, the living room and the bathroom, where there were formations of blisters and spots in the three rooms due to the use of the water used in firefighting. Malfunctions are observed in Figs. 2-4. To correct them mixed lime, 
cement and sand mortar of ratio of 1:1:6 should be applied in the parts that need to be redone, including the areas that were exposed to the chance of new short-circuits. In other stained parts, the paining must be redone (Fig. 5).

\subsection{Upper Apartment}

The damages on the upper apartment are highlighted on the balcony, as the flames reached the border of the damaged window completely, as shown in the detail of Fig. 6. It should soon be made to be replaced and their eventual settlement. The ceramic stone facade around the site, where the frames developed as a result of contact with high temperatures resulting from gases expelled during the fire, may have weakened the mortar of the stones which were also damaged, then were to be inspected by a typical percussion test, so that after identified, must be exchanged.

\subsection{Damages in the Apartment Where the Event Occurred}

The partitions of the apartments were constructed with ceramic sealing blocks with eight holes and the coating was carried out with layers of slurry mortar, grout and paint. Figs. 7-9 show the state of the lining of the walls after the fire, where high temperatures reached the painting and then the mortar conditioning the remaining water present in the element to evaporate, thus increasing the steam pressure and exerting a voltage exceeded the tensile strength of the mortar layer and the side of the sealing block. It is also worth noting that the sinister extinction mode achieved through action by firefighters, influenced the outcome of the constructive elements. Since releasing water to control the firesoaked walls that were mostly dried, would lead to their absorbing and again, having the appearance of internal stresses which tend to expel the peripheral parts of the element [9].

Due to surface wear in the grout and ceramic blocks caused by the situation, the removal of the damaged surface layer is suggested, followed by restoration of masonry, using techniques that employ the use of

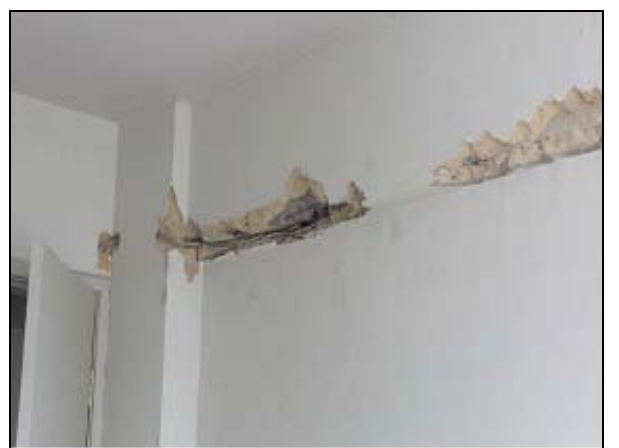

Fig. 5 Inspection of the electrical wiring (the repair must be done with ratio of 1:1:6 cement lime and sand mortar).

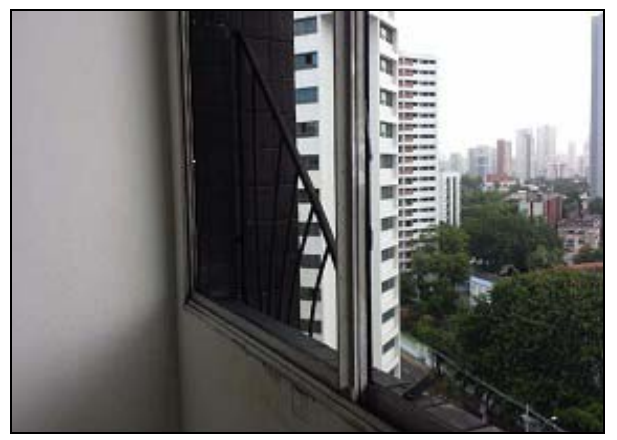

Fig. 6 Detail of the damaged aluminum frame.

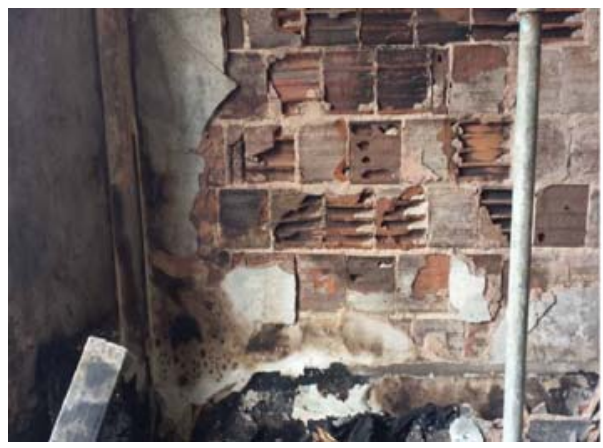

Fig. 7 Bedroom wall: damage to the plaster and coating mortar.

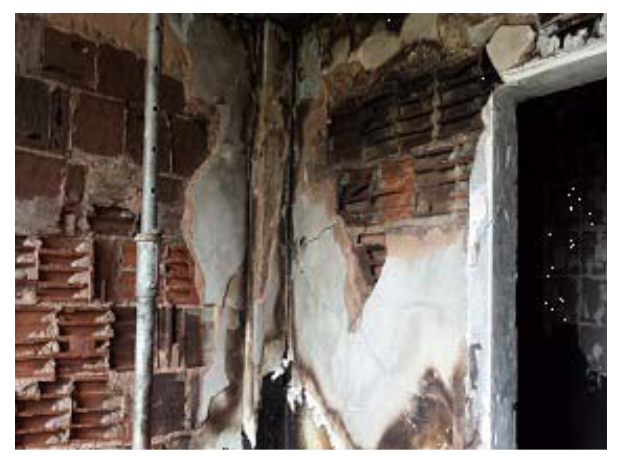

Fig. 8 Outer wall and bathroom partition. 


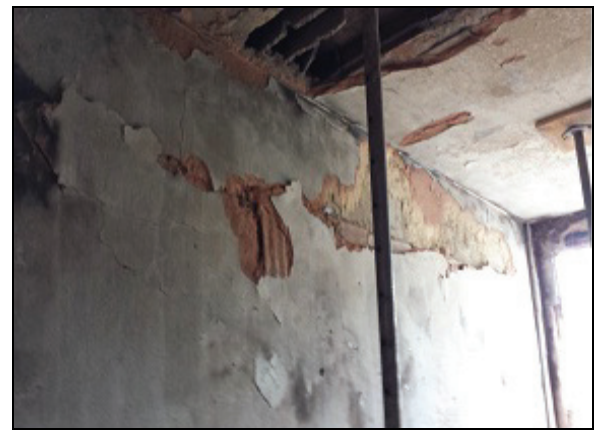

Fig. 9 Damage to the wall and the slab concrete block.

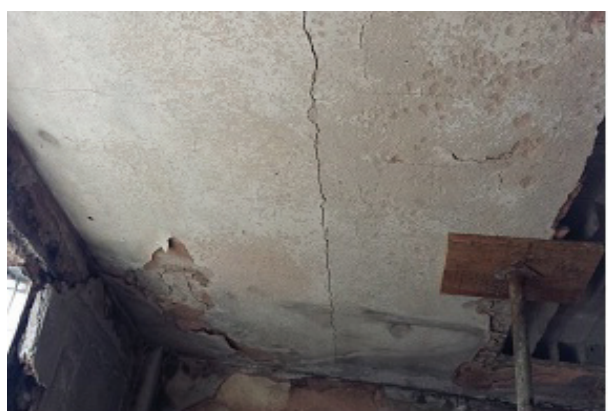

Fig. 10 Apartment ceiling with crack parallel to the ribs.

lightweight concrete in conjunction with polystyrene beads. The application of slurry mortar and plaster mortar with a maximum of $2.5 \mathrm{~cm}$ on the resulting surface is proposed, followed by sealing, spackling, and painting similar to those of other environments.

\subsection{Damages to the Apartment Ceiling}

By analyzing the type of damage that has occurred, we can note evidences showing that the elements suffered effects of spalling and may have developed as explosive spalling or sloughing. It is noteworthy that the elements, ribs and blocks, all precast, are arranged and assembled on the type of slab of the building. The rib is made with the use of small aggregate and fine cement, thus its finish is perfectly smooth, monolithic, which means that the ribs do not have a very strong bond neither with the blocks nor with the resurfacing slab. The high temperatures acted create temperature gradients and eliminate the free water in the concrete members, depending on how the temperature rise was developed. Chipping can be manifested in a way that the surface was slowly degraded with the formation of cracks, where micro pressure generated by the water vapor, evolved a tensile stress in the sense of expelling the peripheral layers of the element. A factor is alleviated by cracks and fissures in the element. If not, the pressure contained within the block tends to increase to a point where it abruptly expelled from the outer layers characterizing the effect of explosive spalling.

Since this is an old building, effects such as clogging of the concrete have appeared by time. That is, the filling of pores, holes, flaws, and irregularities have already occurred and the presence of factors such as the fire was confined to the bathroom and room. One can reach the conclusion that the building blocks near fuel sources such as wardrobe and bed had a higher temperature gradient resulting in cracking and flaking of the peripheries of the parts, since those who were initially removed from the heat source suffered minor gradients temperature, showing surface deterioration resulting from bursts and explosives chipping. There was also fragmentation of the coating layer, with its detachment block ruptures the septa that supported the outer blades, exposed to fire.

There was no evidence of cracks or fissures in the ribs, just a crack in the parallel direction to it (Fig. 10). And the simple structural concrete used in slab capping is insufficient to ensure a high adhesion between the block and the rib, which is justified the surface of the rib hindering the smooth being connection between old and new concrete and the small thickness of concrete between the block and the rib, which easily gives a high percentage of water present in the elements. Because the ribs are smooth, there is also poor adhesion between them and the capping, in a section situated on the rib.

The Volterrana type slabs are ribbed slabs which are a natural evolution of the slab, resulting from the elimination of most of the concrete below the neutral line occupying volume with ceramic bricks of concrete or EPS (expanded polystyrene). This process allows the economical increase in thickness slabs for the creation of voids in a rhythmic pattern arrangement. 


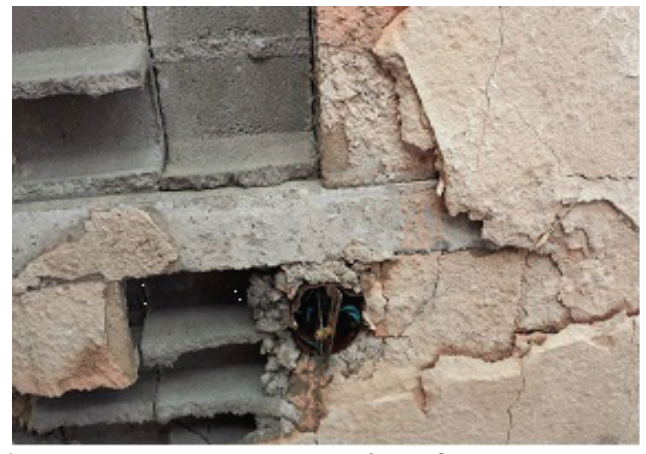

Fig. 11 Damage to the clay coating of mortar and concrete blocks.

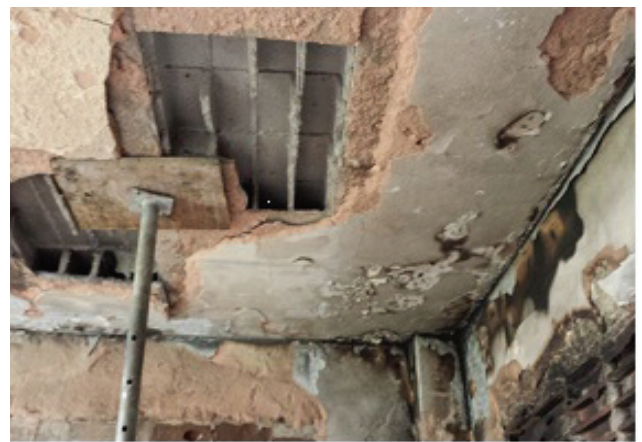

Fig. 12 Damage mortar and clay coating.

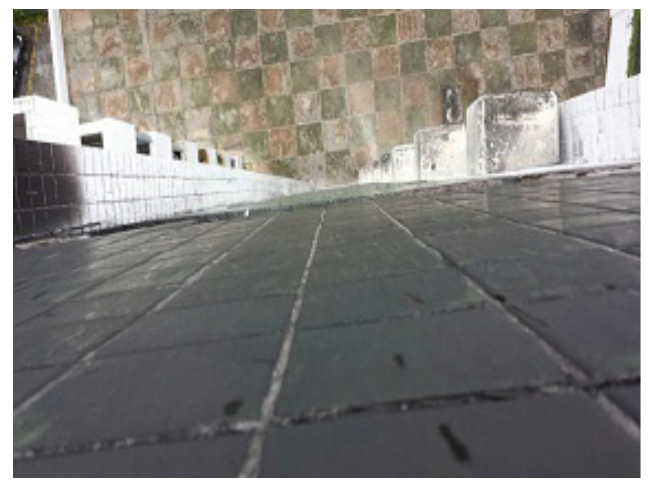

Fig. 13 The exposure to high temperatures damaged the adhesion between the ceramic plate and its substrate.

It thus forms a highly efficient structural system, comprising a set of ribs arranged in one or two directions, with regular spacing between them. Ribbed slabs were designed to have relief from the self-weight of the structure and a more efficient use of steel and concrete. Although these benefits have already been recognized for a long time, the technical means always showed resistance to its use. Today, however, this scenario has completely changed. Technological development has led to the creation of new materials, such as lattice armor and EPS of lightweight blocks, made the use of ribbed slabs a spontaneous solution for the design of structures of multi-story buildings, because of the technical and economic qualities these slabs have.

There was no apparent damage to the slab ribs as seen in Figs. 11 and 12. However, there was no way to access the top of the rib, on which the capping slab is supported. So it is recommended to be made load proof test at the slab region comprising the affected veins [8]. The test should be performed for the project value of overload of use of $150 \mathrm{kgf} / \mathrm{m}^{2}$, which should be measured offsets through gages.

\subsection{Damages to the Ceramic Coating of the Floor and Facade}

On the floor it was observed that the ceramic plates had a hollow sound when knocked on, indicating that due to high temperature and pressure, the ceramic coating lost part of its adhesion to the substrate, Fig. 13 released adjustment layer of the floor.

On the façade, damage was concentrated in the ceramic coating which stood near the window, highlighting the mortar at the top of the frame that had direct contact and continue with the flames, exposing a likely weakness in the system.

Percussion tests are suggested for both situations and once ceramic pieces without proper grip are identified, they must be replaced.

\subsection{Damage in Frames}

The frames of the bathroom and bedroom were completely destroyed by direct contact with the flames, thus were to be replaced.

\subsection{Damages to the Windowsill}

Damages were presented on the windowsill that were highly damaged, holding the mortar to deteriorate laying of ceramic, which naturally should be recovered together with the same. Figs. 14 and 15 show the necessity of retrieving the elements. 


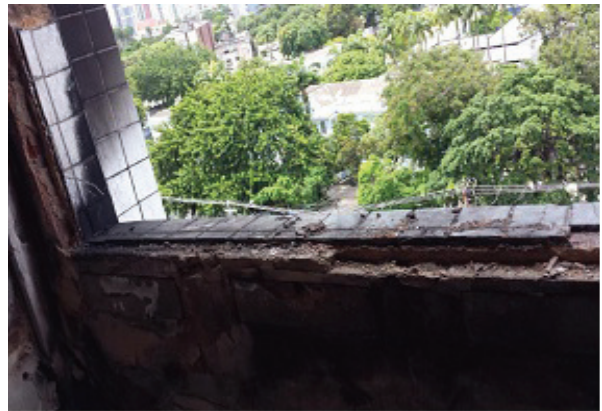

Fig. 14 Details of the damages.

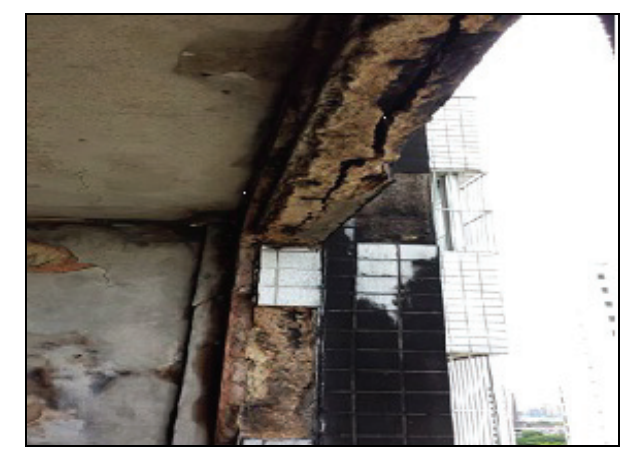

Fig. 15 Detail of the joint recovery point and ceramic plates.

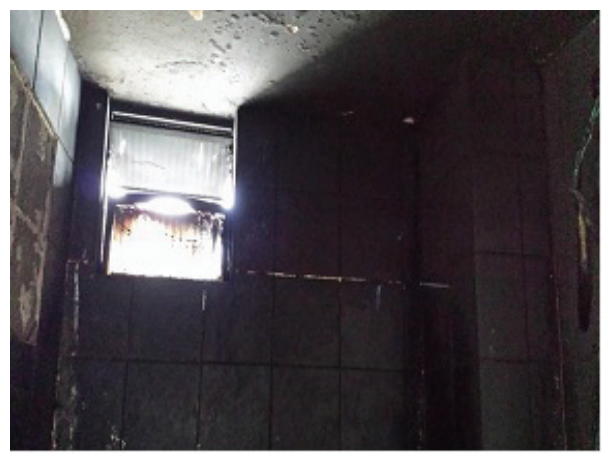

Fig. 16 Damages in the bathroom.

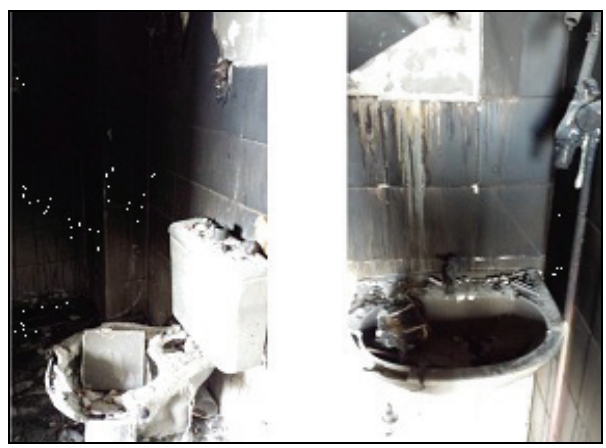

Fig. 17 Details of the damages of the sanitary ware.

\subsection{Damages in the Bathroom}

In the bathroom area, faults were found in the coating of the ceramic walls, on the loss of adherence of the parts to the substrate, also the window, shower, basin, sink and mirror were extremely damaged, necessitating proper exchange of all crockery and metals, electrical, hydraulic, and sanitary system facilities (Figs. 16 and 17).

\section{Conclusions}

Considering the presented arguments, we conclude that:

Because it is a building that presents sealing masonry, damage observed in these elements does not influence at all the structural character of the building, so its recovery is intended only to restore its sealing function between environments. The recovery of the slab is only in aesthetic form, since there no cracks were observed in ribs or arrows beyond normal behavior, and the damage observed on the coating mortar and concrete block does not influence the structural behavior of the slab, because when designed, the blocks are below the neutral axis and the reinforcement rib itself is enough to support the tensile strength. In Volterrana slabs, blocks have the function of only thermal and acoustic insulation to provide comfort to users. Within this principle, interventions in the ceiling slab were recommended. The recommended load test is an important precautionary action to ensure the tranquility and safety of users. The guidelines are aimed at the restoration of finishes that were damaged because the structural characteristics were not affected.

\section{References}

[1] Kodur, V. K. R., and Phan, L. 2006. "Factors Governing the Fire Performance of High Strength Concrete System." In Proceedings of International Workshop Structures in Fires (SIF'06), 709-20.

[2] Rosso, T. 1975. Fire and Architecture. São Paulo: Faculdade de Arquitetura e Urbanismo da Universidade de São Paulo.

[3] Neville, A. M., and Brooks, J. J. 2010. Concrete Technology. England: Longman Group UK Ltd.

[4] Costa, C. N. 2008. "Concrete Elements of Design in Armed Fire Situation." Doctoral thesis, Universidade de São Paulo. Accessed November 10, 2014. 
http://www.teses.usp.br/teses/disponiveis/3/3144/tde-040 92008-155911/pt-br.php.

[5] Costa, C. N., and Silva, V. P. 2006. "Restriction of Effect to Deformations: Mechanical Concrete Elements under Flexion Simple in Fire Situation." Presented at 48th International Congress of Concrete, Rio de Janeiro, Brazil.

[6] Costa, C. N., and Silva, V. P. 2006. "Recommendations for Concrete Elements Sizing the Bending Simple in Fire Situation." Presented at 6th Escola Politecnica University of São Paulo Symposium on Concrete Structures, São Paulo, Brazil.

[7] Fletcher, I. A., Welch, S., Torrero, J. L., Carvel, R. O., and Usmani, A. 2007. "The Behavior of Concrete Structures in Fire." Thermal Science 11 (2): 37-52.

[8] JC Online. 2014. "Fire Destroys Apartment in the Neighborhood of Grace." Jornal do Comercio of Pernambuco. Accessed February 24, 2014. http://jconline.ne10.uol.com.br/canal/cidades/geral/notici a/2014/02/13/incendio-destroi-apartamento-no-bairro-das -gracas-117699.php.

[9] Lima, M., Correa, C., and Oliveira, R. A. 2015. "Risk of Collapse in Case of Fire in Non-structural Masonry Buildings." Buildings-Coffin Type Flammae 1 (2): 28-54.

[10] TV Clube. 2014. "Fire Hits Apartment Building in Thanks." Journal Clube. Accessed February 24, 2014. http://www.tvclubepe.com.br/app/noticia/jornalismo/jornal -da-clube/2014/02/13/noticias_jornaldaclube,92907/incen dio-atinge-apartamento-em-predio-nas-gracas.shtml.

[11] G1 Globe. 2014. "Fire Hits Apartment in Graces, North Zone of Recife." Central Journalism Globe. Accessed February 24, 2014. http://g1.globo.com/pernambuco/noticia/2014/02/incendi o-atinge-apartamento-nas-gracas-zona-norte-do-recife .html?menu=5c719a78bd00b16. 